\title{
Familial clubfoot with or without associated lower limb anomalies
}

INSERM

\section{Source}

INSERM. (1999). Orphanet: an online rare disease and orphan drug data base. Familial clubfoot with or without associated lower limb anomalies. ORPHA:199315

Familial clubfoot with or without associated lower limb anomalies is a rare congenital limb malformation syndrome characterized by malalignment of the bones and joints of the foot and ankle, with presence of forefoot and midfoot adductus, hindfoot varus, and ankle equinus, presenting as rigid inward turning of the foot towards the midline, in various members of a single family. Hypoplasia of lower leg muscles is a frequently associated finding. Patients may present with other low-limb malformations, such as patellar hypoplasia, oblique talus, tibial hemimelia, and polydactyly. 